\title{
Muerte e inmortalidad: lógica de la simiente $v s$. lógica del homúnculo
}

\author{
ANDRES TORRES QUEIRUGA \\ Universidad de Santiago de Compostela
}

El problema de la inmortalidad es replanteado a fondo por la visión emergentista de la antropologia, pues desde ella surgen nuevas dificultades a causa de la vision unitaria que propicia (vivamente resaltadas en Cuerpo y alma por Laín Entralgo). Pero aparecen también nuevas posibilidades. Éstas son las que, atendiendo también a las aportaciones de la teología, intenta explorar el articutlo. Frente a la lógica deductiva y repeti- tiva, que -como en el caso del semenhomúnculo antiguo- sólo puede explicar lo semejante, trata de tomar en su consecuencia la "lógica emergentista", que -como la simiente expandiéndose en el árbol- tiene capacidad para abrirse a la novedad inesperada e irreductible. La lógica de lo nuevo permite además conjuntar indicios de diversa procedencia, que se refuerzan mutuamente en una auténtica circulación del sentido.

\section{Acotamiento del espacio discursivo}

El problema de la muerte se nos presenta siempre complejo, confuso, difícil, disruptor. La muerte constituye un fenómeno paradójico, que es en cierto modo la negación de todo fenómeno. Pues, situada en el límite de todo límite, no puede ser fenómeno para los asistentes, que no pueden vivenciarla en lo que es, sino simplemente contemplarla en sus pródromos o en sus restos; ni siquiera, como ya viera Epicuro, puede serlo para su protagonista, que deja de estar presente en la justa medida en que ella se produce (cuando la muerte está, no está él; cuando está él, no está la muerte).

Si a eso se suma su carácter totalizante, no puede extrañar la afirmación con que Harald Holz cierra un denso artículo al respecto: "La muerte, como fenómeno que afecta de manera única y peculiar la corporalidad y la espiritualidad del ser humano, se desvela como un punto nodal de cuestiones ontológicas, antropológicas, éticas e histórico-filosóficas, cuya solución constituye una larga tarea delante de nosotros».'

En esas circunstancias resulta lógico o bien que el pensamiento quede suspendido en el silencio asombrado y meditativo o bien que -como de algún modo sucede en el libro en tantos aspectos admirable de Vladimir Jankélévitch ${ }^{2}$ se desate en discurso inacabable y retornante de palabras 
que no acaban de cerrarse. Pero ya se sabe que la apuesta del pensamiento consiste justamente en buscar la vía del medio: unas pocas palabras en el bosque del silencio, «senda perdida» o breve demora para el logos.

Aun dentro de ese espacio, este trabajo intenta reducirse todavía a un aspecto muy concreto: hacer algunas sugerencias acerca del tipo de lógica que puede aplicarse en ese límite que parece romper toda lógica. Y lo hará teniendo en cuenta dos referencias fundamentales:

1) Las dificultades y posibilidades que presenta una concepción emergentista, sobre todo teniendo en cuenta la propuesta por Laín Entralgo en su obra Cuerpo y alma. ${ }^{3}$ Intentará encontrar una cierta mediación al dilema con que se enfrenta la asunción de una posible inmortalidad: ver si entre la concepción tradicional del ualma», por un lado, y la "muerte totalı de la persona, por otro, cabe un nuevo tipo de continuidad que evite las aporías que parecen implicar ambas posturas. Conviene, con todo, advertir que se trata ante todo de abrir una nueva posibilidad, no de describirla en su detalle ni de desarrollarla en sus implicaciones.

2) Abierta la posibilidad, interesará, en cambio, mostrar los caminos por donde parece que habrá dé articularse luego la argumentación concreta. Será importante entonces conjugar el rigor lógico respecto del punto central concreto - la posible continuidad - y la conciencia de la importancia que en estos temas envolventes adquieren siempre las pre-comprensiones o «creencias" previas, cuidando de situarlas a su justo nivel (cosa especialmente importante respecto del mundo religioso).

\section{Hacia una logica de la muerte y la inmortalidad}

\subsection{Paradoja y ruptura}

El carácter extraño y paradójico de la muerte es algo que aparece en la superficie misma de la vivencia más espontánea, siempre oscilante entre su naturalidad y su extrañeza. Karl Rahner lo ha expresado bien al afirmar: "La muerte es el fenómeno más universal. Todo el mundo encuentra natural y da por sobreentendido que hay que morir. $Y$, sin embargo, todo hombre vive una secreta protesta contra la muerte y un inextinguible horror ante ellaw. ${ }^{4}$

La verdad es que, por un lado, en cuanto "cesación" de algo que ha empezado, representa lo más universal, pues en ese sentido, según la justa insistencia de Ferrater Mora, "ser real es ser cesables; pero, por otro, en cuanto humana, la muerte se singulariza, convirtiéndose en un usurtido de paradojas", pues el hombre vive asediado por «una frecuente intención de traspasar los límites impuestos por la muerte», por la sed de inmortalidad. ${ }^{5}$ Es la paradoja inscrita en el hecho fundamental y originario de que el hombre, como tantas veces se ha dicho, es el único animal que sabe de 
su propia muerte, pero con un saber que se reduce al hecho, quedando abierto sobre el abismo insondable del qué y del cómo.

Junto a la paradoja está la ruptura. La muerte es la interrupción por antonomasia: tajo sin fondo que suspende el fluir del vivir y del pensar. Es «el instante inenarrable», "fuera de todas las categorías», que "rechaza toda topografía» e interrumpe todas las relaciones. ${ }^{\circ}$ A nivel psicológico es obvio, y valdría la pena repasar, por ejemplo, las páginas admirables de Paul Chauchard acerca de la incomprensibilidad de este hecho "absolutamente distinto de toda experiencia que puedo tener», para el que no existe ninguna analogía. ${ }^{T}$

Pero es sobre todo en el nivel ontológico de la consideración última donde la singularidad de la muerte yergue su interrupción irreversible, que, como enérgicamente observa $\mathbf{E}$. Levinas, marca el carácter inasimilable de su ser "otro", su estar "más allá» de toda lógica de la esencia; hasta el punto de que la muerte parece serlo también de la lógica, pues aparece como lo absolutamente extraño, ruptura de toda identidad, inobjetivable e inefable. ${ }^{8}$

\subsection{Lógica existencial}

De todos modos, el trabajo de la comprensión no puede paralizarse. Desde luego, habrá que mantener abiertas la paradoja y la ruptura, sin cierres apresurados. Pero tampoco basta el silencio mudo ni la mera huida hacia adelante, a lo arbitrario o a lo totalmente ilógico. Lo que cumple es, más bien, el respeto a lo específico en la exploración tanteante, que intenta plegarse a las características peculiares de eso que se ofrece robándose y se presenta escapándose, pero que pertenece a la más íntima entraña de nuestro ser y pide ser traído de algún modo a la palabra.

De hecho, así lo ha comprendido el pensamiento contemporáneo, sobre todo a partir de Heidegger y, en general, del pensamiento existencial. No basta siquiera definir la muerte como algo específicamente humano, sino que, dentro mismo de lo humano, se impone contemplarla en su radicalidad como existenciario último, con su peculiar lógica interna, irreductible no sólo a lo cósico sino también a lo meramente biológico y psicológico. Es bien conocida la importancia decisiva que Heidegger le atribuye: en definitiva, sólo la muerte, en cuanto incluida en la capacidad antícipadora de la cura y desvelada como posibilidad última en la angustia, permite totalizar la verdad de la existencia como un todo. ${ }^{9}$

No interesa ahora discutir lo justo o injusto de toda su tematización, sino únicamente destacar la aportación ya imborrable de que existe un modo específico de acercarse a la muerte. Modo que, sin negar el carácter único y aun la extrañeza irreductible de la misma, no la sustrae sin más al ámbito de la comprensión. Algo que, a pesar de las perspectivas distintas 
en que se encuadran y de las diferentes conclusiones a que llegan, confirman los análisis de Karl Jaspers, de Jean-Paul Sartre y del mismo Gabriel Marcel. Sobre todo el primero, con su tenaz distinción entre «la conciencia en general», es decir el modo de conocimiento objetivante y universal, por un lado, y la "conciencia existencial", por otro, marca tanto la existencia de una lógica específica para la muerte como la necesidad de atenerse a ella, si se quiere vivirla y afrontarla en toda su radicalidad humana. $Y$ destaca mejor que Heidegger el carácter transgresivo de esa lógica, que, por serlo del límite, está ya siempre también más allá del límite. ${ }^{10}$

Todo lo cual cobra todavía una importancia inmensamente mayor al referirse a la «inmortalidad». Por definición, nada de lo que se diga puede ser reducido a las pautas de la realidad empírica: toda proposición rompe necesariamente lo meramente protocolario y remite de modo irremisiblemente alusivo y analógico a algo "otro", en definitiva irreductible e inobjetivable. Jamás podrá tratarse de una "prolongación» o "repetición» indefinida de la vida mortal tal como la experimentamos en el tiempo: eso equivaldría en el fondo a la instauración de un horror infinito.

\subsection{Kontingenzbewältigung}

En realidad, lo dicho podría resultar suficiente para afrontar directamente nuestro problema. Pero existe todavía otro tipo de consideración que arroja una luz muy importante, en cuanto confirma y complementa lo adquirido. Se trata del encuadramiento preciso del problema en la historia general de la cultura. No me refiero ahora a lo que pudiéramos llamar su evolución historiográfica, tal como la describe, por ejemplo, Philippe Ariès en El hombre ante la muerte." Interesa más bien aquel movimiento de fondo que permite dilucidar con claridad los dos niveles fundamentales en que puede moverse la lógica de la muerte: llamémoslos, para simplificar, el científico-técnico y el del sentido último.

Son, en efecto, los dos niveles decisivos que resultan de la decantación cultural inducida por el proceso de la Ilustración. El fenómeno ha sido bien estudiado a propósito de la religión, como un proceso de secularización de la vida y del pensamiento, que retrae y concentra lo religioso en su ámbito específico, distinto de los otros ámbitos y saberes, con su legalidad interna y su lógica propia. Pero la clarificación tiene alcance general, y alcanza, muy en concreto, al problema de la muerte.

No cabe duda de que existe todo un mundo de consideraciones en las que el hombre actual muestra un saber acerca de la muerte, que supera inmensamente al de todas las generaciones anteriores: los procesos fisiológicos que llevan a ella, las enfermedades y los remedios, los síntomas, los indicios y la verificación del fin biológico, los mismos procesos psicológicos... Pero, al mismo tiempo, somos cada vez más conscientes de que exis- 
te otro nivel en el que apenas hemos dado un paso: aquel donde vivimos el asombro del morir, donde se nos abren los porqués del sentido y comprobamos nuestra pasividad última y definitiva. Si en el primer aspecto hemos avanzado espectacularmente, en este segundo no nos diferenciamos gran cosa del hombre de Neanderthal. Acaso nada mejor que pensar en los aparatos de una UCI, magníficos y horribles, portentosos y en definitiva inútiles, para experimentar la profunda verdad de esta constatación.

Este segundo nivel ha sido tematizado recientemente recurriendo a un término de rancio abolengo clásico: el de la contingencia. Es decir, el de aquellas realidades o situaciones -como pueden ser también el nacimiento, o la exposición al azar y a la culpa- en las que el hombre se encuentra ya siempre y que no puede eliminar ni cambiar; lo único que puede hacer es cambiarse a sí mismo frente a ellas. ${ }^{12}$ Tales realidades exigen, pues, una lógica distinta de la técnica o instrumental: una lógica de comprensión y acogida, de libertad e imaginación creativa, de toma de postura ante la propia existencia. (Por eso el nombre que ha entrado en la discusión no es acaso el más adecuado: Kontingenzbewältigung, "dominio de la contingencia»; si bien se nos avisa expresamente de entender bien su significado: "contingencia dominada es contingencia reconocida*.) $)^{13}$

Cualquier lector de Jaspers advierte, por lo demás, que lo dicho se corresponde muy estrechamente con su concepción de las «situaciones límite». ${ }^{14}$ Pero no sobra recordarlo de modo expreso, por dos razones importantes. La primera, porque así aparece a las claras cómo la intuición existencial enlaza de modo intrínseco con el proceso que marca de manera decisiva el destino de nuestra cultura. La segunda porque refuerza la evidencia y la necesidad de una lógica específica para el problema: si, por un lado, habrá de insistir en lo cientifico del concepto de emergencia, por otro, habrá de alimentarse en las intuiciones y categorias específicas de lo personal, siempre abierto e irreductible.

\subsection{Muerte e inmortalidad desde la religion}

Es en esa apertura donde conviene situar bien la aportación religiosa, tan importante en el tema, pero que de ordinario se afronta de un modo incurablemente extrínseco, sin verdadera posibilidad ni de crítica ni de fecundación. Existe, en efecto, un hábito inveterado, que casi se ha convertido en "creencia» evidente, según el cual las verdades religiosas caerían literalmente del cielo. Serian respuestas extra-humanas, ajenas al esfuerzo y al alcance de nuestra racionalidad, que no sólo no engancharían con nuestras inquietudes más íntimas, sino que incluso matarian nuestras preguntas. De ahí se deduce luego que la teología no puede pensar de verdad y que intentarlo sería, en expresión famosa de Heidegger en su ensayo Fenomenología y Teología, postular la existencia de un «círculo cuadrado» o de 
un «hierro de madera».15 Por desgracia, no pocas veces la teología, incluso la última capitaneada en esto nada menos que por el genio de Karl Barth, parece haberle dado la razón: la palabra reveladora caería vertical sobre el hombre y éste no tendría otra posibilidad que la de escucharla sin pedir cuenta ni razón, para lo cual se le regalan incluso los oídos. ${ }^{16}$

Es claro que, de ser las cosas así, los pensadores creyentes se encontrarían en una curiosa situación. Por un lado, jugarían con ventaja: «sabrían" ya por otros caminos aquello que los demás mortales buscan con el sudor de su frente. Pero, por otro, tendrían que aceptarlo pasivamente en el círculo cerrado de su pertenencia grupal y, en caso de conflicto con nuevas evidencias científicas o culturales, resignarse pasivamente a un conflicto de dos fidelidades, sin opción verdadera a buscar una mediación entre ambas. He creído percibir el eco de este conflicto en el libro de Laín, sobre todo en el ejemplar, profundo y sensibilísimo capítulo final. Por eso, aunque es imposible entrar ahora en la compleja entraña de este agudo problema, creo indispensable enunciar - siquiera enunciar- la que, con lo más vivo de la teología actual, estimo visión más correcta de este punto trascendental.

En realidad, se trata simplemente de "volver a la cosa misma" de la religión. Una sencilla reflexión personal y, desde luego, tanto el testimonio de la Fenomenología de la Religión como los resultados de la exégesis crítica, pueden mostrarle a cualquiera que toda religión - y por tanto toda revelación- antes de ser dato ofrecido ha sido dato conquistado en el humanísimo esfuerzo por buscar una respuesta a las preguntas últimas de la existencia. Por eso la religión no cae de arriba, sino que nace de dentro, y todo gran descubrimiento en ella ha brotado del duro esfuerzo de la reflexión, la fidelidad, la oración y el genio de unos pocos. Contra todo tópico superficial, los profetas y fundadores han sido siempre hombres de búsqueda y fidelidad, de crisis y descubrimiento. Piénsese, por ejemplo, en Oseas y Jeremías, en Buda o Zaratustra, o en los treinta años de retiro, indagación y rastreo que preceden al encuentro definitivo de Jesús de Nazaret con su misión propia.

Por eso, cuando el inspirado comunica su descubrimiento a los demás, no les anuncia algo extraño, sino que les llama a reconocer algo que también ellos están viviendo pero cuya profundidad o sentido no habían percibido. En realidad, es lo que sucede en todo descubrimiento "genial" y lo que constituye la perennidad de los «clásicos». Desde hace tiempo vengo tematizando esta concepción hablando de la revelación como "mayéutica histórica»: una palabra descubierta dentro de nuestra historia y que por eso, en aquellos que la admiten, puede hacer de "partera" para, a su luz, reconocer la propia realidad más íntima y profunda.

Esto está dicho así abruptamente y precisaría muchas matizaciones. ${ }^{17}$ Pero acaso baste para percibir lo fundamental: 
1) Que la revelación nace de nuestras preguntas y habla de nuestros problemas; de otro modo ni siquiera podriamos reconocerla. Sería, en expresión genial del joven Hegel, como la predicación de san Antonio a los peces: tan vertical y admirable como inútil y sin sentido. ${ }^{18}$

2) Que por lo mismo, llama al oyente no a aceptar ciegamente, sino a "ver" por sí mismo aquello que le propone. Sócrates decía que él no introducía las ideas en sus interlocutores, sino que, como su madre -maia, "partera"; de ahí umayéutica»-, se limitaba a ayudarles a que las «diesen a luz». Y en el evangelio de san Juan los samaritanos dicen a su paisana: "Ya no creemos por lo que tú nos cuentas; nosotros mismos lo hemos oído y sabemos que él es realmente el salvador del mundon (Jn 4,42).

3) Dado que la revelación se mueve en el nivel del sentido-de "afrontamiento de la contingencia»-, su esfuerzo y su propuesta entran en contacto y diálogo con toda búsqueda humana a ese nivel; muy en concreto, con la filosofía, cuando ésta es de verdad "filosofía primera». En ese terreno específico el esfuerzo del filósofo abierto a los datos de la historia y el del teólogo abierto a las instancias de la crítica convergen, aunque sea asintóticamente, hacia una figura común, én diálogo de enriquecimiento y corrección mutuos. ${ }^{19} \mathrm{El}$ caso del filosofo Jaspers haciendo una filosofía - también de la muerte- empapada de Trascendencia; o el del teólogo Rahner ${ }^{20}$ acogiendo en su estudio las intuiciones de Heidegger, son una buena muestra.

4) Finalmente, esta entrega de la revelación a la interpretación crítica $\mathrm{y}$ al diálogo interhumano, muestra que su propuesta necesita ser continuamente reinterpretada dentro de las coordenadas de cada época y cultura, exponiéndose así a la crítica y a la autocorrección. Lo cual no equivale a negarla o desmentirla, como tantas veces se piensa, tanto desde "dentro", en una ortodoxia estrecha, como desde «fuera», en una descalificación apresurada. Al revés, constituye el único modo de mantener vivo su significado y de entrar con eficacia en el diálogo fecundo de la historia. Es justamente lo que, acaso a pesar de sus propios temores, hace la obra de Laín con sus honestas y lancinantes preguntas finales.

A la luz de estos presupuestos, permítase una importante aclaración terminológica. En este trabajo se habla de «inmortalidad" sin más precisiones. En teología cristiana se habla sobre todo de "resurrección». A este nivel se trata de remitir a lo mismo, con tal de que no se entienda la resurrección como la vuelta a la vida de un cadáver, que continuaría en las condiciones anteriores. Al hablar de "resurrección" o de "vida eterna", lo que de verdad se puede insinuar - como posibilidad analizada o como creencia asumidaes un nuevo modo de vida radicalmente diferente, ya no espacio-temporal (y por lo mismo inimaginable). Cabe igualmente hablar de «esencialización», como lo hicieron el filósofo Schelling ${ }^{21}$ y más tarde el teólogo $P$. Tillich ${ }^{22}$ o de "eternizaciónn: lo decisivo es mantener la apertura a lo nuevo y la conciencia 
de lo diferente. En realidad, sí se piensa bien, de alguna manera una "vida" así, libre de las contingencias de la muerte, tiene que lindar con lo infinito: de hecho, de una cierta «infinitización" habla E. Jüngel ${ }^{23}$ y a ello alude toda idea auténtica de esalvación" religiosa (como misterio absoluto, sólo concebible por comunión con la vida infinita de Dios).

\subsection{El desafio emergentista}

Sobre este ámbito complejo y profundo incide con fuerza la aportación del libro de Laín, que se centra fundamentalmente en el cuestionamiento que la nueva visión científica del mundo ejerce sobre la interpretación tradicional de la inmortalidad. También aquí la evocación de Jaspers muestra la justeza de la pretensión: justo porque la ciencia es "lo otro" de la filosofía y constituye su peligro mortal si llega a imponerle su racionalidad objetivante, debe ser tomada en toda su seriedad, como aquello que conocido, respetado y superado hace surgir la lógica específica de la Trascendencia. ${ }^{24}$ La pregunta por el sentido, incluso por el sentido de las ciencias, "no podría responderse a través de las ciencias mismas».25 Pero, a su vez, "cuando la fe revelada hace afirmaciones en su teología acerca de hechos empíricamente constatables con general validez, pierde toda razón frente a la ciencia metódicamente impositivan. ${ }^{26}$

De ahí la importancia del desafio afrontado en Cuerpo y alma. La nueva visión del universo expuesta en síntesis admirable a lo largo de los capítulos del libro, cuestiona agudamente la dualidad cuerpo-alma como realidades ontologicas distintas, y parece imponer una concepción unitaria "corporalista", "estructurista», "constitucionista" o "emergentista». El autor, que reconoce su irremediable mentalidad cientifica - -Mi pobre mente es científica, y no me es posible evitar que lo sea» (270)-, siente el duro choque con la visión dualista que encuentra en la expresión tradicional de la fe: «los ineludibles, turbadores, insolubles problemas que a la mente científica plantean los textos evangélicos tocantes al orden natural de la realidad creada" (271; cf. 269-272). Como tampoco quiere ni renunciar a su fe cristiana ni vivirla como el «carboneron (270), busca una nueva salida aporética, soportando "newmanianamente* la duda (271), en el reconocimiento de que la alternativa aniquilamiento-resurrección no permite imposición racional unívoca (281).

Presenta la cuestión en su comprometida trascendencia humana, pues no se trata para él de un juego intelectual, sino, literalmente, de una cuestión de vida o muerte. Como Zubiri, vive adentro de sí, intelectual y patéticamente reunidas, la idea científica de la "muerte total" del ser humano y la fe cristiana en la resurrección de los muertos» (143). De ahí que su testimonio llegue a alcanzar ese patetismo humilde y definitivo que ya sólo puede recurrir a Dios como testigo: «Sin jactanciosa seguridad, con temor 
y temblor, porque hablo de Dios y ante Dios, asi entiendo yo lo que como hombre soy" (262).

Ya se comprende que ante un testimonio de este calibre, solo cabe el respeto profundo. Respeto que se hace ante todo silencio. Pero que puede también, en un segundo momento, dejar que germine dentro de él la palabra del diálogo amistoso, donde, en gracia a lo mucho que se ha aprendido, se desearía introducir la pequeña aportación de la propia perspectiva. En mi caso, una perspectiva de téblogo y de filósofo de la religión, que acaso pueda complementar muy bien en algún aspecto la perspectiva del científico y del filósofo humanista.

\section{Lógica de la simiente vs. lógica del homínculo}

\subsection{Dos observaciones generales}

Por mor de la claridad, daré ante todo una impresión general del problema, para centrarme luego en el punto más concreto que intentaré analizar con cierto detenimiento. Esa impresión tiene una doble vertiente.

La primera se refiere a la evidencia "científica" del emergentismo, como prefiero llamarlo, a pesar de las reservas y precisiones de Laín, que prefiere el de uestructurismo» (182-183). Al nivel de generalidad con que aquí lo tomo, es decir, como esa visión evolutiva de lo real, que en complejificación creciente y sin adiciones externas va «dando de sí» nuevos niveles y realidades irreductibles a los anteriores, el emergentismo me parece una evidencia o, mejor, una "creencia" que forma ya parte de nuestros presupuestos a la hora de contemplar lo real. Lain ha hecho muy bien en sistematizar esa evidencia, desde el big-bang cosmogónico hasta su propia peripecia personal. Pero, con los inevitables índices de relatividad que conviene poner siempre en todo lo acientifico", pienso que para mi generación, o al menos para muchos de nosotros que hemos leído a Teilhard cuando nos asomábamos al pensamiento reflexivo y hemos crecido en un ambiente intelectual permeado por la historicidad y la evolución, eso no constituye en rigor una necesidad sino la simple descripción o constatación notarial de un hecho ya acontecido y presente.

Lo cual facilita, por un lado, la coincidencia, y, por otro, acaso tenga la ventaja de dejarnos en algo mejor franquia para pensar lo peculiar de la lógica emergentista. De hecho en ese punto preciso es donde intentaré centrar las reflexiones finales.

Pero antes es preciso aludir a la segunda vertiente. Si la primera era más bien generacional, ésta es directamente teológica. Después de lo antes insinuado a propósito de la revelación, se comprenderá bien lo que quiero indicar con la siguiente observación: los filosofos, cuando son creyentes, tienden a mirar con excesivo respeto a la teología -a la teología, no a la 
fe-, no atreviéndose por lo general a un cuestionamiento legítimo de su racionalidad (que tal como de ordinario la reciben está casi siempre por debajo de la que manejan en su filosofia). De hecho, gran parte del agobio de Laín nace de una lectura excesivamente tímida y literal de los datos revelados. Así da por supuesta la realidad de la resurrección de Lázaro (274), que es más bien una narración simbólica o parábola en acción; y que además, de ser cierta, carecería de relevancia, pues nada tendría que ver con la vida eterna sino con la mera vuelta a la vida de un cadáver, que habría de morir de nuevo... ${ }^{27}$ Y lo mismo cuando acerca de Jesús ve tropiezo científico y filosófico con «todo lo que de su cuerpo -encamacion, resurrección, ascensión-y de su obra - multiplicación de panes y peces, resurrección de un difunto- tan expresamente" se le dice (269); e igualmente en «lo que sucedió en el vientre de María y en el cuerpo ascendente de Jesús» (270).

No cabe entrar ahora en prolijos detalles exegéticos. Pero sí es preciso indicar que la verdad profunda que con esas verdades de fe se quiere expresar en modo alguno es solidaria de la imaginería precrítica y cientifista con que se presenta ordinariamente. (El resucitado, por ejemplo, no era visible ni material, ni tenía sentido que ascendiese o bajase espacialmente, porque no hay cielo arriba ni infierno abajo, ni es eso lo que quieren decir los evangelios; de hecho, Lucas en su evangelio sitúa el símbolo de la ascensión en la tarde del mismo domingo de Pascua, mientras que al comienzo del Libro de los Hechos, también escrito por él y remitiéndose expresamente a la narración anterior - Hch 1,1-3-, lo sitúa cuarenta días después: señal inequívoca de que no pretendía ser tomado a la letra.)

Es decir, esas expresiones de la fe pertenecen a un discurso distinto del científico y filosófico. No se trata, pues, de situar uno al lado del otro, sino de mediar el primero con el segundo, para hacerlo comprensible hoy. En ese esfuerzo consiste justamente una de las tareas de la teología. La mediación podrá ser acertada o no, pero intentarla no es atentar contra la fe, sino prestarle el mejor servicio posible. En este sentido, creo que Laín manifiesta demasiados temores - rsentada mi tesis corporalista, no es tarea fácil la conciliación entre ella y mis creencias» (272)-, cuando la verdad es que su libro hace en este punto muy lúcida y valiosa teología. Sus preguntas al respecto son las de todo teólogo que tome en serio la situación actual. Su propuesta ilumina puntos importantes y acaso deje alguno en la sombra. Acerca de ello - dejando ya de lado todo temor exegéticointentan decir algo las reflexiones siguientes.

\subsection{Hacia una logica emergentista consecuente}

La visión emergentista y unitaria tiene la ventaja de la coherencia con el desarrollo evolutivo de lo real, pero debe afrontar el espectro siniestro de la "muerte total", que, con Zubiri, asombra a Laín. Ésta, como interrup- 
ción absoluta, parece cuestionar la posibilidad misma de una vida eterna. Si la muerte es total, parece desaparecer todo soporte intrínseco para una posible continuidad. Porque, si del que muere no queda nada, ¿quién resucita? Lo que pueda aparecer más allá del abismo de la muerte, será un doble del que ha vivido o su copia clónica, pero no él mismo. ${ }^{28}$

Ésta es la cuestión que inquieta la entera andadura de Cuerpo y alma. Pero el libro la asume, porque no le ve otra alternativa que la de recaer en el viejo dualismo. Y no cabe dudar de su seriedad. Ahí está «la horrible evidencia del cadáver», ${ }^{29}$ que, para la conciencia normal, parece decidir a su favor. Para la conciencia filosófica $M$. Theunissen, prolongando una aguda reflexión de $\mathrm{W}$. Schulz, ha mostrado que esta totalización de la muerte responde a una profunda tendencia del pensamiento moderno: el "fin de la metafísica", que ya no parte de la división cuerpo-alma, ${ }^{30}$

$Y$ en el ámbito teológico toda una parte de la moderna teologia protestante y algunos católicos, como bien recuerda el mismo Laín, sostienen esa teoría, concibiendo la resurrección como una re-creación apoyada en la amorosa fidelidad de Dios: Karl Barth lo expresó enérgicamente al afirmar que lo que queda tras la muerte «no es ni un algo divino ni un algo creatural, sino un obrar y un haberse (Tun und Verhalten) del Creador respecto de su creaturas. ${ }^{31}$

Desde luego, la cuestión es profunda y espinosa. Ni siquiera es posible entrar aquí en el agudo problema de la identidad personal. ${ }^{32}$ Sólo pretendo que, sea ella lo que sea, no parece concebible en nuestro caso sin una continuidad ontologica entre el que muere y el que, a través de la muerte, se encuentra "resucitado": algo tiene que hacer de "soporte" o "mediador" entre el primer "yo vivo" y el ulterior "yo sigo encontrándome vivo". Se trata claramente de un auténtico "abismo de la razón», pero no se trata aquí de explicarlo, sino, mucho más modestamente, de mostrar algo que deber estar implicado en toda posible explicación.

Ciertamente, desde las pautas empíricas y desde la lógica "normal" no resulta fácil escapar al dilema con que se enfrenta Laín: de un lado, salvar el abismo lógico de la interrupción absoluta que parece seguirse de la visión emergentista -abismo que personalmente no veo la posibilidad de mantener si se quiere sostener la identidad personal-; de otra, afirmar un "soporte" de la continuidad, recayendo para ello en el viejo dualismo cuerpo-kalma». Pero tal vez la salvación de la dificultad pueda venir justamente de la raíz misma del peligro: de la visión emergentista plenamente asumida.

$\mathrm{Y}$ acaso la cuestión radique, justo, en ese "plenamente", es decir, en llevar a sus últimas consecuencias la nueva lógica que ahf se anuncia. Th.S. Kuhn nos ha acostumbrado a ver que en toda "revolución" - "científicas o no científica, añadamos- - el viejo paradigma cede, de entrada, sólo lo indispensable y tiende por todos los medios a reducir a sus propios 
esquemas las consecuencias que se derivan del nuevo. En el problema que nos ocupa, la tendencia inconsciente es fatalmente la de seguir juzgando con la lógica continuista y preevolutiva las consecuencias que brotan del paradigma emergentista. De ahí que el pensamiento que pretende asegurar algún tipo de continuidad tienda, sin darse cuenta, a concebirlo bajo pautas que de un modo o de otro corresponden al «alma» del antiguo paradigma fixista.

Por eso conviene precaverse. Concretamente, aquf es preciso acentuar dos vectores fundamentales: por un lado, el carácter necesariamente abierto e indeterminable de lo nuevo que aparece; $\mathrm{y}$, por otro, la constitutiva versión de su dinamismo no sobre el pasado sino sobre el futuro.

Lo primero es meramente formal, pero muy importante. Por definición, lo emergente resulta siempre incomprensible desde los parámetros del estadio previo: ¿quién, examinando sólo la materia inorgánica y sin haber visto jamás una brizna de vida, podría siquiera imaginar desde aquélla lo que ésta es en su increíble novedad?, ¿quién podría predecir el roble en la bellota? Una vez visto lo nuevo, sí, resulta factible, aunque no siempre fácil, trazar líneas de cierta continuidad con lo anterior y adentrarse lentamente en su inteligibilidad interna. Pero proceder al revés significa imposibilitarse de raíz para la comprensión de lo nuevo y de su misma posibilidad. Hasta el punto paradójico de que aquí la verosimilitud continuista resulta índice infalible de error e imposibilidad de conocimiento auténtico.

Pues bien, hagamos la aplicación: si existe un emerger de la vida mortal hacia el ámbito cualitativamente distinto de una inmortalidad futura, es obvio que debemos contar con que ésta no puede sernos inteligible en su posible figura concreta. Encima, no se trata de una emergencia cualquiera, sino de una emergencia con dos características que la acentúan hasta lo literalmente indecible: 1) se trata de la exaltación de toda emergencia, del extremo mismo del entero emerger cósmico, biológico y humano; 2) carecemos de todo acceso al examen directo de su resultado.

En esas circunstancias no sólo no debe extrañar la oscuridad en que nos movemos, sino que es preciso reconocerla como auténtico criterio de cualquier verdad posible en este ámbito: de ser posible, sólo lo será así. Una figuración concreta, sería un signo inequívoco de que no se trataba de un salto emergente a un estadio radicalmente nuevo. De ahí la incomodidad de todo pensamiento crítico ante todo tipo de representaciones de un «más allán como mera prolongación, más o menos disfrazada, del "más acá».

El segundo vector es igualmente importante. Sabemos muy bien que la visión tradicional situaba lo perfecto y principial en el pasado. Sólo con la Ilustración se nos ha ido imponiendo el futuro como verdadero centro de gravedad (todavía Kant consideraba "más nueva, pero mucho menos extendida» la opinión del progreso hacia el futuro). ${ }^{33}$ Pues bien, al buscar 
un soporte para la posible continuidad, nuestros hábitos mentales se vuelven con demasiada facilidad hacia el pasado: hacia un alma que desde el comienzo lo estaría organizando y dirigiendo todo. Cuando lo obvio en una lógica emergentista es dirigirse al futuro: hacia algo nuevo que se genera y aparece en el proceso, posibilitando o forzando el salto hacia adelante. Piénsese en el paso de la materia a la vida: no había algo previo que organizase el cambio, sino, al contrario, este fue promovido por la aparición de un nuevo medio y de una nueva complejidad interna; sea lo que sea, ha aparecido después, en el proceso mismo de la evolución. Y, a su vez, la continuidad de la vida se asegura justamente por la simiente, que no viene de antes, sino que es producida por el organismo después de una necesaria maduración (tanto más delicada y compleja, cuanto más elevada es la vida).

La aplicación parece clara. El «algos que pueda sostener la continuidad hacia lo inmortal no tiene por qué ser concebido como una realidad previa, al modo del «alma» tradicional. En esto estriba lo justo de la negación de Laín, en coherencia con su planteamiento. Pero, al tiempo, la lógica emergentista parece permitir y aun postular algo más: que, de haber inmortalidad, ésta sea promovida o al menos posibilitada por algo nuevo, que aparece en el mismo proceso constituyente de la vida humana. Ese «algos tiene que sernos de algún modo presente, puesto que es el lazo de continuidad; pero no puede dibujársenos con claridad, puesto que no nos es dado contemplar la figura expandida de su realización efectiva: no podemos dibujar el árbol de la vida eterna, porque sólo tenemos su semilla; a lo sumo podemos presentirlo, porque la semilla es promesa.

Hay todavía algo más: la simiente no tiene sentido sin un contexto que la promueve y la apoya. Sola no podría nada: únicamente en cuanto engranada con otras realidades y apoyada en otros factores puede dar origen al milagro de la nueva vida. Con la muerte humana será preciso esperar algo análogo: la inmortalidad sólo es pensable en un contexto global y abarcante, que apoye la frágil soledad humana, permitiéndole otro tipo de germinación. No podemos imaginarlo, pero al menos brilla mejor la coherencia de su posibilidad. Y, de hecho, veremos cómo la argumentación indirecta cobra aquí una importancia decisiva.

En general, cuando se enfoca así el problema, se tiene la sensación de que todos los datos cobran un nuevo dinamismo y resulta posible organizar mejor su dispersión aparente. De hecho, en la escala de la vida el ansia de inmortalidad aparece como algo nuevo, generado en el proceso de la filogénesis humana: «el hombre es el único ser que ha soñado con ser inmortals ${ }^{34} \mathrm{Y}$ esa ansia encuentra siempre su mejor caldo de cultivo en la comunión abarcante del contexto religioso o de la solidaridad cósmica y humana. Sin que, a la vez, todo ello pueda borrar la insuperable indeterminación de lo emergente. 
El subtítulo del trabajo pretende justamente subrayar la importancia decisiva de esta lógica específica. Una visión tradicional muy frecuente veía el germen varonil humano como un "homúnculo" que prefiguraba en pequeño la exacta realidad del adulto, retrayendo así al pasado lo que es fruto del trabajo del tiempo hacia el futuro. Hoy hemos aprendido a verlo como "simiente", como epigénesis de lo nuevo: quien pretendiese examinarlo a nivel figurativo para adivinar lo que de ese germen saldrá, no vería «nada», y, si se dejase llevar por la lógica del homúnculo, acabaría negando toda posibilidad de un nacimiento futuro.

No es osado afirmar que sólo así cabe definir las características irrenunciables de toda reflexión sobre el problema. No puede aspirar a la lógica deductiva de lo hecho y acabado, sino que ha de saberse abierta a lo nuevo, en un proceso tanteante e inductivo. Se tratará, pues, de una lógica de la invención, donde juegan la fantasía creadora, la prolongación del indicio, la convergencia de probabilidades y la búsqueda asintótica de una coherencia global, en un terreno donde la razón y la libertad confluyen y se fecundan mutuamente. Un discurso humilde, complejo y difícil, pero cuyo estilo constituye la marca de todo lo auténtica y profundamente humano.

Acaso por eso sean los poetas los que mejor lo expresen, tanto en la desposesión de su incertidumbre: «Nadie ha vuelto de la muerte para decirnos si morir es como caer la hoja que se pudre o como caer la semilla que renace», ${ }^{35}$ como en su doble, humanísima marca de esperanza: «siam la mort una maior naixença", ${ }^{36}$ y de nostalgia: "Quizabes para isto non facía falla / que Deus te despertase e fixese a luzm.37

\section{La «evidencia» de la inmortalidad}

Claro está que con lo dicho sólo quedan patentizados los caminos de la posibilidad. No se ha probado la inmortalidad, sino algo mucho más modesto: que no es absurda y que es posible intuirla como promesa posible en el horizonte de la vida humana. ¿Cabrá dar un paso más, hasta recoger indicios y razones concretas que permitan también una afirmación -que será también necesariamente fe y apuesta, adivinación y esperanza- de la realidad?

Ya se comprende que no es éste el lugar para intentarlo siquiera. Lo que a continuación voy a decir, aspira únicamente a insinuar por donde en mi parecer puede transitar un planteamiento acorde con las premisas expuestas. Los posibles argumentos son de dos tipos: unos que buscan evidencias en algún modo directas y otros que siguen un camino indirecto. No es preciso jerarquizarlos: en realidad se reúnen y entrelazan, confirmándose o neutralizándose, en esa visión global que en definitiva decide las últimas evidencias o las decisivas negaciones. 


\subsection{La evidencia (más) intrinseca}

Dentro de esta lógica específica, las razones de la inmortalidad humana no adquieren un valor apodíctico, pero pueden alcanzar su verdadero significado. Abierto el ámbito de la posibilidad, resulta más factible un tanteante acercarse a la (de)mostración de su realidad.

En realidad, con las "pruebas" de la inmortalidad sucede algo parecido a lo que Hegel dijera acerca de las de la existencia de Dios: igual cabe afirmar que son miles como que son una sola, pues todas son en el fondo variaciones de una misma intuición radical. En el caso de Dios, lo son de la contingencia; en el de la inmortalidad, del carácter trascendente con que la realidad humana aparece desbordando la frontera de la muerte. Desde Kant y Hegel, sobre todo, es bien conocida la distinción entre el límite como «frontera" (Grenze) y como «cese estático» (Schranke). En el primer sentido, el reconocimiento de un límite, supone ya de algún modo su superación. Y esa superación es justamente lo que caracteriza la vivencia humana de la muerte frente a la «resignación» animal, a la «insensibilidad» vegetal o a la "pasividad" mineral.

No cabe duda de que ahí está la raíz última de donde brotan los diversos barruntos y las múltiples representaciones de la inmortalidad. Como hecho, esa transgresión está contenida en el fenómeno mismo de la anticipación de la muerte, y en ese sentido es reconocida incluso por las concepciones más finitistas como la del propio Sartre. ${ }^{38} \mathrm{El} \mathrm{mismo} \mathrm{Heideg-}$ ger de Sein und Zeit, tan proclive al finitismo, afirma expresamente esa apertura, al dejar bien claro que su análisis no decide sobre el sí o el no de la inmortalidad. ${ }^{39}$ No hablemos ya de las posturas más transgresivas como las de un Ernst Bloch, de cuya teoría del homo absconditus nace la ontología del "todavía no" que trabaja y determina el núcleo más decisivo de la realidad: "no nos sería posible sufrir de este modo por lo deficiente, si algo en nosotros no nos impulsase más allá, no resonase más profundamente, no nos arrastrase por encima de todo lo corporal...".40

En esta perspectiva cabría doblar la afirmación de Max Scheler acerca de la "evidencia de la muerte" en la vivencia misma de la vida, ${ }^{4 !}$ con la simultánea afirmación de una «evidencia de la inmortalidad». Si aquélla se muestra en el oscuro percibir cómo se contrae continua e irremediablemente el conjunto de lo que podemos vivir, ésta aparece en la incesante y transgresiva ampliación de ese conjunto como anticipación de la inmortalidad.

A este respecto no deja de ser curioso y hasta sorprendente el hecho de que esta dimensión que culmina el conocido ensayo de Georg Simmel, Para una metafisica de la muerte, ${ }^{42}$ haya sido descuidada por Heidegger, que tanto desarrolló la primera. Para Simmel la experiencia de la muerte, que anticipada en la vida la define al finitizarla, hace destacar también sus 
contenidos significativos que la llevan a su máxima elevación: «en tanto que da cabida a éstos o se vierte en ellos, que son más que ella misma, la vida escapa por encima de sí, sin perderse, es más, ganándose auténticamente por vez primera" (60); y, a la par: "tanto más decididamente se marca el Yo como lo Uno que persevera en todas las oscilaciones pendulares del destino y del representar el mundo", concentrándose cada vez "más puramente en sí mismon (60-61). En esta concentración es donde enraíza "el pensamiento acerca de la inmortalidad", pues por este costado aparece cómo la muerte no interrumpe ula exigencia del Yo a perfeccionarse eternamente o a existir ulteriormente» (61). De este modo, después de una observación crítica -en mi parecer injusta- acerca de la concepción religiosa de la inmortalidad, Simmel puede concluir su ensayo: "allí donde, por así decirlo, se busca la forma pura de la inmortalidad, allí aparecerá la muerte ciertamente como la frontera más allá de la cual caen del Yo todos los aducibles contenidos particulares de la vida y donde su ser o su proceso es un mero pertenecerse-a-sí-mismo, una pura determinabilidad por medio de sí mismo» (62).

Me he extendido algo en la un tanto abstrusa exposicion, porque hay todavía en este razonamiento otro aspecto importante. Simmel, aunque sin tematizarlo de modo expreso, habla de este Yo con plena «consecuencia emergentistan, pues lo pone siempre hacia delante, en expresiones dinámicas de producción, decantación, profundización, aproximación. Se muestra además sensible a la constitutiva apertura e indeterminación de la categoría: «el proceso vital anímico total hace evidente con creciente desenvolvimiento la imagen cada vez más clara y más fuerte que puede denominarse el Yo. [...] este Yo está en una peculiar categoría, todavía necesitada de una representación más próxima; es una tercera categoría más allá de la realidad dada y de la irreal, meramente exigida, idea de valor" (60).

Scheler, a diferencia de Heidegger, sí que prolonga sus finos análisis de la evidencia de la muerte hacia la percepción de la inmortalidad. ${ }^{43}$ Insiste sobre todo en la "vivencia de impulso" (Schwungserleben) o "sobrepasamientow (Überschuss), por la que la persona se proyecta a sí misma "más allá de la destrucción de su cuerpo» (46-47). Llega incluso a afirmar que éste es «el dato esencial íntuitivo" (das intuitive Wesensdatum) que funda toda idea de inmortalidad (47). También sitúa la posibilidad de modo emergente: al revés de la materia que va de uuna máxima libertad hacia una máxima atadura, que coincide con la muerte», el espíritu marcha "desde la atadura máxima por las necesidades vitales hacia la entrega cada vez vitalmente más libre al puro contenido de las cosas, valores y personas» (48).

Sin embargo, con justa cautela, no se atreve a hablar de evidencia: sólo afirma ese sobrepasamiento: «no sé nada más» (Mehr weiss ich nicht) (48). En cuanto a la inmortalidad, pertenecería ya a la "fe puras (49), que 
para él es fe religiosa. Este último dato y el carácter, digamos, emergentista tanto de su razonamiento como del de Simmel, adquieren una significación que nos permite enfocar ya el último tramo de nuestra reflexión.

En efecto, si la inmortalidad se enfoca de modo estático o aislado, acentúa casi hasta lo insoportable su aspecto de oscuridad o aun de inverosimilitud extrema. Sólo reconocida, por un lado, como posible emergencia hacia lo nuevo y necesariamente indeterminado $y$, por otro, incluida en contextos que hagan de mediación a su racionalidad, cabe destacar su aspecto más «evidente» y lograr acaso esa "certeza libren, propia de todo lo emergente. En este sentido, habrá que retomar y precisar, de un modo algo distinto al de Scheler, el rol de lo religioso.

\subsection{La evidencia mediata}

La verdad es que, como realidad personal, la muerte no puede considerarse algo aislado: el sentido que pueda tener ha de venirle necesariamente del vasto y complejo entramado de relaciones en que se ubica. De hecho, con mayor o menor conciencia explícita, este dato es casi siempre tenido en cuenta. Procediendo ya de modo esquemático, cabe introducir una cierta sistematización, que permita aprovechar su evidencia, intentando unirlas en una visión global. Insisto, con todo, en que se trata de meras insinuaciones: cada una de ellas pediría un desarrollo por separado.

1) El contexto cósmico-vital tiene desde los presocráticos una fuerte presencia $y$, sobre todo a partir del romanticismo, ha influido siempre en nuestra cultura. Lo ha hecho sobre todo una vez que se ha impuesto la evidencia de la evolución tanto cósmica como biológica: piénsese en pensadores tan influyentes como Bergson y Teilhard de Chardin, o incluso en las consideraciones de E. Morin al respecto. ${ }^{44} \mathrm{La}$ vida humana como momento de una corriente global, que la abarca, la integra y la lleva más allá de sí misma, tiene una honda sugerencia de verdad a la hora de comprender la muerte no como mera negación sino como tránsito a una mayor plenitud y universalidad. Aquí cabría integrar también la rica y secular sugerencia de las teorías, sobre todo orientales, de la transmigración con su sentido de una circulación cósmica de la vida. ${ }^{45}$

Su límite puede estar en mirar hacia atrás, volviendo el dinamismo sobre sí mismo, anulando lo nuevo y tendiendo más bien hacia la disolución en lo impersonal: las reflexiones de Freud acerca del sinstinto de muerte" como tendencia a la recuperación de la indefinición inicial lo muestran claramente; ${ }^{46}$ y lo mismo sucede en definitiva con su original y sutil prolongación en $\mathrm{G}$. Bataille.47

Esta intuición se hace más fecunda cuando se encuadra en lo personal. La comunión interhumana, al expandir la vida, la afirma en sí misma y la lanza hacia adelante: desde «el amor es fuerte como la muerte" del 
Cantar de los Cantares $(8,6)$ hasta el "amar a alguien, es decirle: tú no morirás” de G. Marcel, ${ }^{48}$ aparece ahí una evidencia cálida y siempre renovada.

2) Evidencia que se prolonga y fortalece cuando lo interpersonal se expande en lo ético. No sólo al estilo de Kant como mediación del postulado de la inmortalidad en la conciencia individual. Sino sobre todo en cuanto la ética incluye nuestra vinculación intrínseca a los demás. Tal en la responsabilidad por el otro, como con tanta energía muestran las reflexiones de E. Levinas. ${ }^{49}$ Tal las diversas propuestas del marxismo humanista, que, de diversas maneras, intuyen en la entrega a la comunidad humana la ruptura de los límites en que la muerte parece clausurar al individuo. ${ }^{50} \mathrm{Tal}$, finalmente, el énfasis de la teología de la liberación en el Dios del amor que no s6lo afirma ya ahora la dignidad y apoya la lucha de los oprimidos, sino que asegura la justicia de su salvación.

3) Está finalmente la mediación religiosa, que acaso ahora pueda ser comprendida en su verdadero significado. El situarla como «mediación» la coloca ya en su debida luz. Porque indica que se trata de una aproximación específica, con su lógica propia, pero que responde a una búsqueda humana: es lo que desde su perspectiva encuentra el hombre religioso, porque le convence y puede por lo mismo presentarla como uoferta mayéutica" a todos los demás.

Se entiende bien, concretándonos al ejemplo de la Biblia. La idea de resurrección no cae hecha y derecha de un cielo revelador. Supone una durísima conquista reflexiva, que cuenta con importantes influjos de las culturas circundantes, que incluye crisis tan terribles como la reflejada en el libro de Job y que sólo tras largos siglos, muy cerca ya de la era cristiana, encuentra sus primeras formulaciones. Por eso puede seguirse y contrastarse el camino de su lógica, que se apoya en el amor fiel de Dios al hombre. Resulta además altamente significativo que la lógica de este amor se le hace efectiva por dos vías complementarias: por un lado, acaba comprendiendo que Dios es capaz de sostener contra la muerte vínculo de amor que le une al hombre (véase, por ejemplo, el Salmo 73); por otro, que ese amor tiene poder para rescatar de la muerte a los fie. ; víctimas de la injusticia (cf. Daniel y el libro segundo de los Macabeos).

Como se ve, se trata de la misma lógica interpersonal ética que encontrábamos antes, sólo que ahora centrada en eel gran prt mo», Dios, que tiene poder para hacer efectiva la intuición que ya allí st ios abría. Y no deja de resultar fascinante observar cómo en las últimas estribaciones de la reflexion sobre los grandes problemas de la muerte individual y de la destrucción histórica, son justamente estas ideas las que reaparecen, como se ha visto en los grandes de la Escuela de Frankfurt: sólo desde una Trascendencia salvadora cabe esperanza para las víctimas. ${ }^{51}$

4) A esta altura sería fascinante adentrarse en la dimensión ontologi- 
ca que se abre desde Dios para la inmortalidad. El hombre es indisoluble pero inconfundiblemente realidad biologica y realidad personal. La muerte evidencia que la inmortalidad biológica es imposible, aunque destaca de sí misma, a través de la simiente, esa cierta inmortalidad que es el hijo. Pero propiamente la inmortalidad, de darse, sólo puede ser en lo personal, que es ciertamente lo que nos define como humanos y donde, concluida la evolución biológica, prosigue nuestro avance: de ahí la preemiencia omnímoda y creciente de lo cultural y el recurso a los valores personales para definir la grandeza o la miseria de un hombre o de una mujer.

Pues bien, la peculiarísima relación ontológica con Dios, tan agudamente percibida por las religiones, como fondo absoluto que sustenta nuestro ser contingente y relativo, permite intuir y aclarar de algún modo la posible continuidad de nuestro ser. Porque Dios no es una realidad al lado de la nuestra, que se le sumase homogéneamente, sino el non-aliud cusano, que es distinto de nosotros en cuanto no lo es y por tanto nos incluye y hace ser. La comunión con Él en el ámbito de lo personal, tan inaprehensible empíricamente pero que nos define de modo decisivo, asegura el espacio de la continuidad. La dialéctica del amor que fascinaba al joven Hegel, en la que uno se recibe del otro, deja entrever el misterio de ese recibirse plena y enteramente desde el Dios ya desvelado que constituye la salvación. Acaso a esto alude - sin explicitar suficientemente su calado ontológico- la teoría re-creacionista mentada, al buscar nuestra continuidad en la acción de Dios, en su creador relacionarse con nosotros. Y ciertamente a esto -igual que el "todo en todos» paulino $(1$ Cor 15,28$)$ apunta toda la vehemencia de la visión oriental -hindú, budista, taoístaal concebirnos como wapariencia* de lo Absoluto, aliento de su Aliento (atman-Atman/Brahma): «eso eres tú (tat twan asi), unión no dualista (advaita)...

Las últimas consideraciones suponen, claro está, que se cuenta de algún modo con la existencia de Dios. $Y$, en efecto, siempre he abrigado la convicción de que la existencia de Dios es más clara para nosotros que la inmortalidad humana. ${ }^{52}$ Pero no es esto lo decisivo. Lo importante es que también esa convicción responde a la misma dinámica: la existencia divina no es una producción caprichosa o una revelación arbitraria, sino que nos resulta accesible por los caminos de una lógica específica pero humana. Puede por lo mismo confluir con otros caminos. Pues la elaboración del sentido no es un proceso estático, de perspectivas meramente yuxtapuestas, sino que de ordinario se produce en ella una auténtica circulación de las perspectivas.

De ahí que pueda incluso invertirse el camino de la evidencia, con tal de que no se mezclen los inicios ni se confundan los trayectos. Partiendo de otra angulación, cabe argüir, como tantas veces se ha hecho, desde el ansia de inmortalidad hacia la existencia de Dios. No hay círculo vicioso, 
sino angulaciones distintas que recorren itinerarios diferentes, pero que siendo todos nuestros pueden integrarse en una figura común, que entonces irradia su luz sobre las perspectivas parciales.

En definitiva, aquí se hace evidente un importante aspecto de la logica emergentista. Dado que se trata de explorar lo desconocido, dinámicamente abierto ante nosotros, todos los indicios se polarizan hacia adelante, iluminándose mutuamente. No puede esperarse desde luego la claridad contundente del mediodía, sino el lento y plural germinar de la aurora. Pero, justo por ello, una vez despierta la sensibilidad y debidamente seducados los ojos», como le gustaba decir a Teilhard, todo puede convertirse en indicio y promesa, que es como suele realizarse siempre lo más humilde y grandiosamente humano.

\section{NOTAS}

1. H. Holz, «Tod», Handbuch philosophischer Grundbegriffe, 5, Münich, 1974, 23.

2. La mort, París, 1977.

3. Cuerpo y alma. Estructzora dinámica del cuerpo humano, Madrid, 1991.

4. Sentido teologico de la muerte, Barcelona, 1965, 60 .

5. J. Ferrater Mora, El ser y la muerte, Barcelona, $1979^{2}, 53$.

6. Las expresiones aluden a epígrafes de V. Jankélévitch, op. cit., parte II, cap. 1, 219-255.

7. La mort... et puis apres?, Paris, 1967, 31; cf. 27-44; «Ma mort et mois.

8. Cf. «La mort et le temps", en Cahiers de l'Heme: Emmanuel Levinas, París, 1991, $21-75$.

9. Cf. principalmente El Ser y el Tiempo, México, 19712, 50, 272-275.

10. Cf. principalmente Philosophie, II, Berlin / Heidelberg / Nueva York, 19734, 220-230.

11. Madrid, 1983 (el original es de 1977).

12. Cf. H. Lübbe, Religion nach der Atfflutrung, Graz/Viena/Colonia, 1986, 127-218, que, con matices diferentes, alude también a F. Kambartel y a N. Luhmann.

13. Ibid., 166.

14. Cf. op. cit., cap. 7, 201-254.

15. Phänomenologie und Theologie (1927), en Wegmarken, GA 9, 1976, 45-78; la expresion ahölzemes Eisen", en p. 66; de "circulo cuadradow habla en Nietzsche II, Pfullingen, 19614, 132.

16. Sobre la cuestion, cf. A. Torres Queiruga, uTeoloxia e pensamento en Heidegger. Reflexión desde a provinciam, Grial, 27 (1989), 315-339.

17. Lo he estudiado con detenimiento en La revelacion de Dios en la realizacion del hombre, Madrid, 1987 y, más sintéticamente, "La comunicación humana de la revelación divinaw, en A. Dou (ed.), La comtunicacion, Madrid, 1991, 211-231 (233-241: coloquio sobre la ponencia). 80,426

18. "La positividad de la religión cristiana", en Escritos de Juventud, México, 1978, 78,

19. Trato de elaborar de modo expreso esta propuesta en A. Torres Queiruga, La constitucion modema de la razón religiosa. Prolegomenos a una Filosofia de la Religion, Pamplona, 1992.

20. Op. cit. y numerosos escritos posteriores, sobre todo, Curso fundamental sobre la fe, Barcelona, 1979, 495-513.

21. Cf. explicación y referencias en H. Fuhrmanns, Schellings letzte Philosophie, Berlín, $1940,232-233$. lling).

22. Teología Sistemática, III, Salamanca, 1984, $480-481$ (remite expresamente a Sche- 
23. Morte, Brescia, 1972, 169-173. Atendiendo tambien a otra tradición religiosa, ideas semejantes aparecen en R. Panikkar, El sitencio det Dios, Madrid, 1970, 47-53, 71-80, 254-257.

24. "La diferenciación entre las "realidades" cognoscibles con valor general y las experiencias no impositivas racionalmente, pero que, no obstante, se hacen presentes impositivamente según otro sentido en construcciones, imágenes e intuiciones, sólo llego a ser clara gracias a la pureza de la ciencia modema. Y asf diferenciamos dentro de la inmanencia misma las cosas conocidas o cognoscibles, de las cifras» (La fe filosófica ante la revelacion, Madrid, 1968,271 ; cf. 87-96).

25. Ibid, 91 .

26. Ibid, 93 .

27. En este sentido es fina la observación de J. Saramago en su novela $O$ Evangetho segundo Jesus Cristo, Lisboa, 1991, 428: María Magdalena acaba convenciendo a Jesús de que no resucite a Lázaro, pues «Ninguém na vida teve tantos pecados que mereça morrer duas vezes».

28. Asi arguye con energía J.V. Arregui, El horror de morir. El valor de la muente en la vida humana, Barcelona, 1992, 396-397.

29. Asi la he calificado yo mismo en un artículo ya algo lejano: «Recuperar la experiencia de la resurrección», Sal Terrae, 70 (1983), 196-208.

30. Die Gegenwart des Todes int Leben, en Negative Theologie der Zeit, Francfort, 1991. 197-217, en pp. 198-199, 210-211. Remite a W. Schulz, "Zum Problem des Todes", en A. Schwan (ed.), Denken im Schatten des Nihilismus, Darmstadt, 1975, 313-333.

31. Kirchliche Dogmatik, vol. IJ/2, Zollikon/Zurich, 19594, 428.

32. Cf. la excelente exposición que de la discusión anglosajona en este punto hace $\mathrm{E}$. Romerales, Alguntos problemas relativas a la supenvivencia post-mortem, comunicación al XVII Foro sobre el Hecho Religioso, Madrid, 1993, pro man.

33. La religión dentro de los limites de la mera razón, Madrid, 1969, 30; se refiere inmediatamente al progreso moral, pero la observación tiene claro alcance universal.

34. J. Ferrater Mora, op. cit., 134.

De hecho, no es casual la asociación de la angustia con la radicalización de la mortalidad; y nadie sabe mejor que Laín Entralgo de la afinidad profunda entre esperanza e inmortalidad (cf. La espera y la esperanza, Madrid, 196233, parte III, cap. I, 275-329).

35. J. Camer, cit. por J. Ferrater Mora, ibid, 208.

36. J. Maragall, cit. por Laín, 281 , cita otro verso que refleja bien la slogica de la simientew.

37. A. Cunqueiro, "Herba aquí e acolá", en Obra en galego completa I Poeska. Teatro, Vigo, 1980, 176. Cunqueiro, a quien horrorizaba una simple prolongación infinita de la vida, se definia como «de la tribu de los esperanzados nostálgicos», y era gran "creedor» en la resurección: "¿ ¿Podríamos enseñarle al hombre, que aun cuando la nieve cubra el mundo, la rosa esta siempre aguardando la hora? $*$.

38. Liêtre et le neant, Paris, 1943, 615-638; se trata, sin duda, de "la part incontestable de véritén que tienen esas teorias $(616-617$; cf. 630-633).

39. El Ser y el Tiempo, op. cit., 49, 270-271.

40. Geist der Utopie (1923). Francfort, 1973, 315. Tomo la cita de J.L. Ruiz de la Peña, Muerte y marxismo humanista, Salamanca, 1978, 53; en los diversos autores estudiados en esta obra puede verse muy bien la fuerza del carácter transgresivo de la anticipación. Sobre Bloch ver también J.J. Tamayo Acosta, La muerte en el ntarxismo. Filosofta de la muerte en $E$. Bloch, Madrid, 1979, y Religion, razon esperanza. El pensamiento de E. Bloch, Estella, 1992, 223-249. $16-21$

41. "Tod und Fortleben", en Schriften aus dem Nachlass, vol. I, Bema, 1957", 11-64; esp.

42. Puede verse en El individuo y la libertad. Ensayos de critica de la cultura, Barcelona, 1986, 55-62; la primera redacción es de 1910, refundido luego en "Tod und Sterblichkeits, en Lebensanschauung, Múnich/Leipzig, 1918.

M. Theunissen, loc. cit., 213-215, no ha dejado de señalar que la posición de su pensamiento sobre este problema es «unicas en la modernidad. 
43. Ibid., 36-49.

44. El hombre y la muerte, Barcelona, 1974. CE. también las alusiones de Lain a ralgunos pensadores y hombres de ciencia - Richet, Toynbee, Koestler, no pocos miembros de la Society for Psychical Research" (276).

45. Les presta mucha atención la rica obra de J. Hick, Death and Etemal Life, Londres, 1985, 279-398.

46. En este sentido su postura va contra toda la evidencia emergentista: "Un instinto seria, pues, una tendencia propia de lo orgánico vivo a la reconstrucción de un estado anterior que lo orgánico tuvo que abandonar» ( «Más allá del principio del placer», en Psicologta de las masas, Madrid, Alianza, 1986, 112; cf. 112-137, donde todo tiende a mostrar que «la meta de todo es la muerten). Cf. las observaciones de J.V. Arregui, op. cit., 260-265.

47. Cf principalmente Teoria de la religión, Madrid, 1991 y El erotismo, Barcelona, 1992. CE. la enérgica síntesis de J. Juanco, La muerte y lo sagrado: G. Bataille, comunicación al XVII Foro sobre El Hecho Religioso, Madrid, 1993, pro man., que alude también a las teorías, afines a su modo, de F. Savater y E. Trías.

48. Le Mort de demain, acto 2.", esc. 6." (en Trois Pièces, Paris, 1931, 161).

49. Cf. loc. cit. 68-74. Para él, que desarrolla su reflexión en constante referencia polémica a Heidegger, «La mort de l'autre, c'est. la mort première" (38).

50. Acaso su relación negativa o ambigua con la Trascendencia hace que en algunos autores se mezcle con la subida hacia la comunidad humana una cierta vuelta hacia la integración cósmica: cf. al respecto J.L. Ruiz de la Peña, op. cit.

51. Cf. la sintesis de R. Mate, La razón de los vencidos, Barcelona, 1991, y M. Fraijo, Fragmentos de esperanza, Pamplona, 1992, 105-138.

52. En este sentido nesulta significativo el diálogo de la Katha Upanishad, 1, 20-21. Nakiketas le pregunta a Yama (el dios de la muerte, que le ha concedido tres deseos; éste es el tercero) si también el alma muere o no con el cuerpo, obtiene como respuesta: «En este punto incluso los dioses han dudado. No es un tema fácil de comprender. Te ruego que escojas otro deseo, oh Nakiketas, y no me obligues a responder» (Las Upanishads [versión de C. Vallcorba], Bancelona, Edicomunicación, 1988, 23). 